\title{
O público leitor como comunidade de interesse e ponto de partida para novas estratégias de letramento e promoção da leitura
}

\author{
Readers as stakeholders and starting point for new literacy \\ and reading promotion strategies \\ RAQUEL BELLO VÁZQUEZ \\ UniRitter \\ Rede Galabra \\ raquel.bello.vazquez@gmail.com \\ https://orcid.org/0000-0002-1054-8198 \\ MAICON CAMARGO \\ UniRitter \\ maiconcamarrgo@gmail.com \\ MARINA EGGRES \\ UniRitter \\ marinaeggres@hotmail.com
}

\section{RESUMO}

O trabalho sintetiza a primeira fase de um projeto sobre práticas e discursos relativos à leitura no Brasil comparando consumos literários reais e o corpus sancionado academicamente e, em consequência, a proposta (implícita e explícita) de modelo de consumo literário, no que diz respeito aos produtos que deveriam ser lidos e às formas em que eles devem ser consumidos.

Para a elaboração dos resultados utilizamo-nos de dois métodos:

a) A coleta de dados sobre leituras obrigatórias em provas de acesso ao ensino superior e as citações de produtores em trabalhos acadêmicos e livros didáticos, possibilitando uma correlação entre estes elementos e seu resultado dentro do cânone.

b) A análise e discussão dos resultados da pesquisa Retratos da Leitura no Brasil (Failla, 2016), em comparação com as listas de mais vendidos de diversas editoras e as leituras obrigatórias dos vestibulares de universidades com programas de pós-graduação com nota máxiam (7) pela Coordenação de Aperfeiçoamento de Pessoal de Nível Superior (CAPES) de 2015 a 2017.

Palavras chave: Literatura como Prática; Comunidades de Leitura; Consumos Culturais; Cânone Escolar. 


\begin{abstract}
This paper summarizes the first stage of an on-going research project on practices and discourses on reading through the comparison of actual literary consumption and the academic legitimized corpus which turns to become an explicit or implicit proposal of the set of products that should be consumed and at the same the ways that consumption should be done.

For elaborating the results two methods were used:

a) The collection of data on mandatory readings in tests for admission on Federal Universities, and number of citations of literary producers in academic papers and books as indicators of their level of canonization.

b) The analysis and discussion of some of the outcomes of the research Retratos da Leitura no Brasil (Portraits of Reading in Brazil, Failla, 2016), establishing a comparison with the best-sellers lists of several publishing houses and, again, with the mandatory readings for admission in the top federal universities (acording to the federal agency CAPES) for the years 2015 a 2017.
\end{abstract}

Keywords: Literature as Practice; Literary Communities; Cultural Consumption; Scholarly Canon.

\title{
1. A LEITURA NO CONTEXTO BRASILEIRO
}

O Brasil considera o acesso à leitura um direito, e para tal fim estabeleceu em 1992 o Programa Nacional de Incentivo à Leitura (PROLER), o qual

tem por finalidade contribuir para a ampliação do direito à leitura, promovendo condições de acesso a práticas de leitura e de escrita críticas e criativas. Isto implica articular a leitura com outras expressões culturais, propiciar o acesso a materiais escritos, abrir novos espaços de leitura e integrar as práticas de leitura aos hábitos espontâneos da sociedade, constituindo, dentro e fora da biblioteca e escola, uma sociedade leitora na qual a participação dos cidadãos no processo democrático seja efetiva (“Sobre o Proler”).

A tradição da interpretação da literatura como direito, consagrada por um dos nomes mais relevantes da teoria literária brasileira, Antonio Candido (2004), agente fundamental no processo de canonização de estéticas e períodos literários como o modernismo e norteador dos estudos literários no país, deve ser compreendida no contexto de uma rampante carência de letramento, social e politicamente motivada, dentro de um sistema em que grandes grupos populacionais não têm acesso a condições básicas de cidadania, entre elas, um ensino público de qualidade.

Longe de qualquer pretensão moralizadora, o nosso entendimento do que devem ser políticas de promoção da leitura está baseado na identificação da leitura como aspiração social, conforme mostra a pesquisa Retratos da Leitura (Failla, 2016: 87-89), onde se recolhe uma pergunta que de várias formas norteia e instiga a pesquisa aqui apresentada: diante do questionamento sobre o que significa a leitura, 17\% das pessoas inquiridas assinalaram que "ler ajuda a vencer na vida", com uma prevalência de $15 \%$ entre pessoas leitoras e $19 \%$ entre pessoas não leitoras. Esta ideia fica (ainda mais) reforçada à vista dos resultados desagregados por nível de escolaridade, pois quanto menor é a formação, mais elevada é a percentagem de adesão: $26 \%$ das pessoas não escolarizadas, $20 \%$ das que têm apenas o ensino fundamental incompleto, $17 \%$ com o fundamental completo, 
$15 \%$ das que concluíram o ensino médio e $11 \%$ das que possuem ensino superior. $\mathrm{O}$ mesmo pode dizer-se relativamente ao nível socioeconômico, pois concordam com esta afirmação $23 \%$ das pessoas pertencentes às classes $\mathrm{D} / \mathrm{E}, 16 \%$ da classe $\mathrm{C}, 12 \%$ da classe B e $10 \%$ da classe A. ${ }^{1}$

Existe, portanto, uma correlação entre a situação de vulnerabilidade social e econômica e a crença na leitura como um meio de melhorar as condições de vida e de acesso a direitos, o que nos leva a interpretar estes dados como a expressão de um desejo de maior acesso à leitura e às vantagens que se percebe que ela pode trazer.

Concordamos com Torres Feijó (2016) em que não se trata de modo algum de que exista uma bondade ética intrínseca à pessoa leitora ou à atividade da leitura, mas um conjunto de benefícios associados a ela que são identificados pelas pessoas em situação de maior vulnerabilidade social, enquanto são dados por supostos por quem desfruta plenamente desses direitos, ou seja, as denominadas classe A e B, e pelos detentores de diploma universitário. Pesquisas recentes como a de Luís Paulo Arena (2018), baseadas nos avanços de Castrillón (2011) e Petit (2008, 2011 e 2013), corroboram através de depoimentos de usuários e usuárias de bibliotecas comunitárias a mesma percepção de correlação entre a leitura literária e o acesso à cidadania plena.

Estes dados devem ser entendidos no contexto de precário letramento no Brasil, tal e como vários relatórios públicos, como a Avaliação Nacional de Alfabetização, a Pesquisa Nacional por Amostra de Domicílios 2007/2015 conduzida pelo IBGE, e a Avaliação nacional da alfabetização do INEP e o Indicador de Analfabetismo Funcional (INAF) do Instituto Paulo Montenegro. Da terceira, e mais recente Avaliação Nacional de Alfabetização (2017) depreende-se, para a população infantil, que mais de 50\% das alunas e alunos inquiridos encontram-se em níveis insuficientes de leitura (níveis 1 e 2) e menos de $13 \%$ chegam ao nível 4 ("desejável”) para o conjunto do Brasil.

Para maiores de 15 anos, o IGBE computa como analfabeta $8 \%$ da população brasileira. Embora este dado suponha uma descida com respeito a 2007, em que o percentual era de $10,1 \%$, a pesquisa do INAF eleva até $27 \%$ o percentual de pessoas analfabetas funcionais (o somatório das pessoas não alfabetizadas mais aquelas que têm uma alfabetização denominada "rudimentar"). Daquelas que são alfabetizadas funcionalmente, convém salientar que o grupo maioritário é o elementar (42\%), sendo consideradas "proficientes" apenas $8 \%$ das pessoas inquiridas.

Failla (2016), seguindo a metodologia CERLALC-UNESCO, considera pessoa leitora aquela que leu um livro ou parte dele nos últimos três meses, o qual evidencia a pertinência da análise de Márcia Abreu (2001: 54) em relação a muitos discursos de promoção da leitura (particularmente os escolares) que promovem uma ideia de leitura certa vs leitura errada, com o livro como símbolo da primeira:

1 O IGBE classifica as classes sociais pela renda familiar. A classe E é aquela que ingressa até 1 salário mínimo (954 R\$/mês), a classe D recebe entre 1 e 3 salários mínimos, a classe C de 3 a 5, a classe B de 5 a 15 salários mínimos, e a classe A é aquela que supera os 15 salários mínimos de renda mensal. As classes C, D e E equivalem a um $80 \%$ da população brasileira. 
A delimitação implícita de um certo conjunto de textos e de determinados modos de ler como válidos, e o desprezo aos demais estão na base dos discursos que proclamam a inexistência ou a precariedade da leitura no Brasil. É leitor apenas aquele que lê os livros certos, os livros positivamente avaliados pela escola, pela universidade, pelos grandes jornais, por uma certa tradição de crítica literária, ainda que os critérios de avaliação, poucas vezes explicitados, estejam vinculados a noções particulares de valor estético, de cidadania, de conhecimento. Todos os demais escritos - mesmo que materialmente idênticos aos livros certos - são não livros. Da mesma forma, aqueles que os leem - embora leiam - são não-leitores, pois leem Sabrina, leem Paulo Coelho, leem literatura popular.

Nesta lógica que reduz a prática leitora a um modelo único vinculado com o contexto burguês capitalista, como apontado por Lajolo e Zilberman (2003: 16), e como afirmam Horellou-Lafarge e Segré (2010: 96),

subentende-se que o livro é o símbolo da leitura e o meio valorizado, legítimo, de acesso à cultura, ao saber, aos conhecimentos, oferecendo assim às categorias sociais modestas a perspectiva de uma ascensão social à qual aspiram e dando aos integrantes das classes populares que privilegiam a leitura de revistas em detrimento dos livros o sentimento de não serem leitores. ${ }^{2}$

As circunstâncias enumeradas levantam questionamentos éticos, pois políticas públicas são desenhadas levando em conta o cânone literário e as interpretações textuais estabelecidas pela academia. Os curricula escolares, provas de acesso ao ensino superior (ENEM e vestibulares) e ações de promoção da leitura e do letramento são apenas algumas destas políticas.

\section{METODOLOGIA}

A coleta de dados fundamentou-se em pesquisas que visam a reflexão respeito aos índices de leitura brasileiros, como o projeto Retratos da Leitura no Brasil a partir das suas três últimas edições. O trabalho também se propôs a um estudo quantitativo-qualitativo, buscando em dados estatísticos o fortalecimento do corpus da pesquisa.

Foram examinados artigos que se debruçam sobre os índices de livros mais vendidos no intuito de estabelecer a sua relação com o cânone literário no Brasil ${ }^{3}$ (EBLE:

2 As mesmas autoras comentam a função "ostentatória" do livro nos salões burgueses (Horellou-Lafarge e Segré, 2010: 138).

3 Optamos especificamente pela denominação "cânone literário no Brasil" e não "cânone literário brasileiro" para evitar a confusão entre o funcionamento de um cânone de produtos legitimados, fundamentalmente pela escola, com as fronteiras e definições da literatura nacional. Para o caso em estudo, determinados produtos literários da tradição escolar portuguesa produzidos no período da 
2014), além de material online para sustentar não somente a incidência de autores dentro das leituras obrigatórias de vestibulares, mas também no âmbito científico, tangentes ao número de citações em pesquisas acadêmicas e livros didáticos.

Focando particularmente na última edição do Retratos da Leitura (Failla, 2016), interessou-nos averiguar qual é a literatura presente na vida do interrogado, as motivações por trás de suas escolhas e inclusive descobrir quais são os autores de sua preferência. Para tanto foram selecionadas para análise as questões 19, 41 e 42.

Estas informações foram relacionadas às listas de leituras obrigatórias dos vestibulares realizados por Universidades públicas ou privadas cujos programas de Pós-Graduação em Letras são nota 7 na avaliação realizada pela CAPES, ${ }^{4}$ a fim de identificar a presença de produtos e produtores canonizados e requisitados para o acesso ao ensino superior no consumo ${ }^{5}$ efetivo da população.

A pesquisa Retratos da Leitura (Failla, 2016) mostra que os dois tipos de textos mais consumidos no Brasil são livros religiosos e espirituais e best-sellers internacionais, com especial incidência de textos adaptados para a mídia audiovisual. A presença da literatura brasileira pertencente ao campo da produção restrita ou erudita, "que se constitui como sistema de produção que produz objetivamente apenas para os produtores" (BOURDIEU, 2005: 105) em várias listas de livros mais desejados, preferidos ou influentes é geralmente fraca, mas consistentemente é aquela (clássica ou contemporânea) incluída nas listas de leitura dos vestibulares. Estes foram uma ferramenta utilizada na Reforma Universitária normatizada na Lei n. 5540 em 1968, durante o período militar brasileiro, para mascarar a falta de vagas no ensino superior. São exames classificatórios em que apenas os alunos com notas mais altas nas áreas específicas do curso desejado são admitidos. Visto que o sistema de seleção para as universidades públicas manifestava (e continua a manifestar) um forte viés de classe e raça e, procurando amenizar estes efeitos, em 2012 foi efetivada a lei 12.711, que oficializa a reserva de vagas a ingressantes oriundos de escolas públi-

Colônia ou outros, como pode ser a lírica medieval, obras de Luís de Camões, Camilo Castelo Branco ou Eça de Queirós conformam o cânone escolar da literatura no Brasil. Do mesmo modo, autores contemporâneos africanos (de forma particular José Eduardo Agualusa, Mia Couto, Pepetela e Ondjaki) têm vindo nutrir os curricula escolares como parte do cumprimento da lei $\mathrm{n}^{\circ} 10.639$, de 9 de janeiro de 2003, promulgada pelo Presidente Lula da Silva, que altera a Lei n 9.394, de 20 de dezembro de 1996, que estabelece as diretrizes e bases da educação nacional, para incluir no currículo oficial da Rede de Ensino a obrigatoriedade da temática "História e Cultura Afro-Brasileira".

Na mesma lógica, ao falarmos do mercado literário não nos interessará a diferenciação entre literatura brasileira ou estrangeira, mas as preferências expressadas pela aquisição de títulos, independentemente da sua procedência ou língua original de publicação, pois o nosso foco está no funcionamento do sistema e não na aplicação de critérios de classificação nacionais.

4 A Coordenação de Aperfeiçoamento de Pessoal de Nível Superior é a agência federal responsável pelo financiamento e avaliação dos programas de pós-graduação de Instituições de Ensino Superiro, públicas e privadas, no Brasil.

5 Falamos deliberadamente de consumo e não leitura efetiva pois podemos saber o que as pessoas declaram saber ou o que é comprado segundo listas de vendagem (ambas constituindo formas de consumo) mas não fazemos equivaler este consumo à leitura no sentido convencional. 
cas, com baixa renda familiar e de grupos étnicos histórica e socialmente marginalizados (negros e indígenas principalmente), embora algumas Instituições de Ensino Superior já tivessem implementado um sistema próprio de cotas.

No contexto do vestibular, as leituras obrigatórias geralmente são aplicadas nas provas de Português e de Literatura, como, por exemplo, na Universidade Federal do Rio Grande do Sul (UFRGS), em que as disciplinas variam de peso 1 (10\%) a 3 (30\%), a prova de Língua Portuguesa conta com peso $3(30 \%)$ para todos os cursos e a de Literatura com pesos que variam de 1 a 3 , dependendo do curso pretendido.

Já o ENEM (Exame Nacional do Ensino Médio) foi criado em 1998 para avaliar e qualificar a aprendizagem nacional, mas com o passar dos anos foi sendo modificado e, para além de possibilitar o acesso à faculdade através do ProUni (Programa Universidade para Todos) e do Sisu (Sistema de Unificação Qualificada), chegou a substituir o vestibular de algumas universidades federais (Universidade Federal do Mato Grosso, Universidade Federal do Rio de Janeiro, por exemplo). Mesmo que nos últimos anos instituições de ensino superior tenham aderido ao exame, algumas seguem reticentes por ele conter questões mais amplas e que possibilitam a compreensão de alunos com diferentes habilidades. Nele é necessário também um certo conhecimento de obras canonizadas na prova de Língua Portuguesa, mas não é algo que marque todas as 45 questões ou que seja obrigatório.

Os dados mostram que quando depende do critério do público leitor no Brasil este prefere os best-sellers internacionais (geralmente vinculados a produtos audiovisuais como filmes ou seriados de TV) ou livros pertencentes à temáticas como espiritualidade, religião e autoajuda (Failla, 2016, p. 31 e 94). Esta preferência pode ser expressa não apenas na compra, mas também na requisição de livros em bibliotecas, na realização de comentários em sites dedicados na internet, por exemplo.

Na última seção do artigo discutimos esta questão à luz do conceito "Responsabilidade Social Investigadora" definido por Torres Feijó (2015) como

o compromisso de compartilhar os resultados e as explicações do processo de pesquisa com os sujeitos humanos envolvidos nela e/ou com os setores sociais potencialmente interessados ou afetados pelos resultados. Uma definição genérica de RSI poderia defini-la como o compromisso adquirido pela instituição de pesquisa com as comunidades que estão potencialmente interessadas ou são afetadas pela pesquisa. Falamos de análise de resultados e explicação para nos referir a aquelas ações que levam ao entendimento das questões de pesquisa e os seus objetivos, os processos seguidos para chegar a resultados e a informação que deles se deriva [tradução nossa]. ${ }^{6}$

6 "The commitment to share results and the explanations of the research processes that lead to them with the human subjects involved in it and/or the social sectors potentially interested in or affected by those results. A generic definition of SRR [Socially Responsible Research] could describe it as the commitment acquired by a research entity with the communities that are potentially interested in or affected by its research. We talk about result analysis and explanation in order to refer to those actions that lead to the understanding of research questions and their objectives, the processes used to arrive to the results and the information derived from them". 


\section{RESULTADOS E DISCUSSÃO}

Os dados apurados resultaram em questionamentos quanto ao que de fato estaria ligado às práticas de consumos culturais, além de levantarem indagações sobre o papel da literatura nestas práticas e a presença do cânone não somente na academia, mas na formação de um perfil para o leitor brasileiro.

Corroborando com as informações contidas na pesquisa Retratos da Leitura..., a tabela de livros mais vendidos evidencia uma grande concentração de títulos do gênero espírita e autoajuda entre os mais consumidos, e uma gama significativa de best-sellers contemporâneos, literatura blockbuster e livros relacionados a personalidades da internet ou do meio artístico em geral; ao mesmo tempo, mostra a ausência de produtos canonizados no âmbito brasileiro (independentemente do seu lugar/contexto de produção), fazendo-nos perguntar qual o seu papel dentro das práticas de leitura e qual o perfil do/a leitor/a brasileiro/a.

Na tabela abaixo é possível perceber que entre os exemplares com maior número de vendas os seis primeiros títulos pertencem ao gênero de autoajuda/filosóficos: Batalha Espiritual, O homem mais inteligente da história, O poder da ação, Sapiens: Uma breve história da humanidade, Por que fazemos o que fazemos e Propósito. O mesmo tipo de literatura mais voltada à reflexão e de autoajuda - torna a aparecer alguns títulos depois em Ansiedade: como curar o mal do século, O poder do hábito, O poder do agora, Minutos de sabedoria e Os segredos de uma mente milionária, sendo o gênero que mais aparece nos índices.

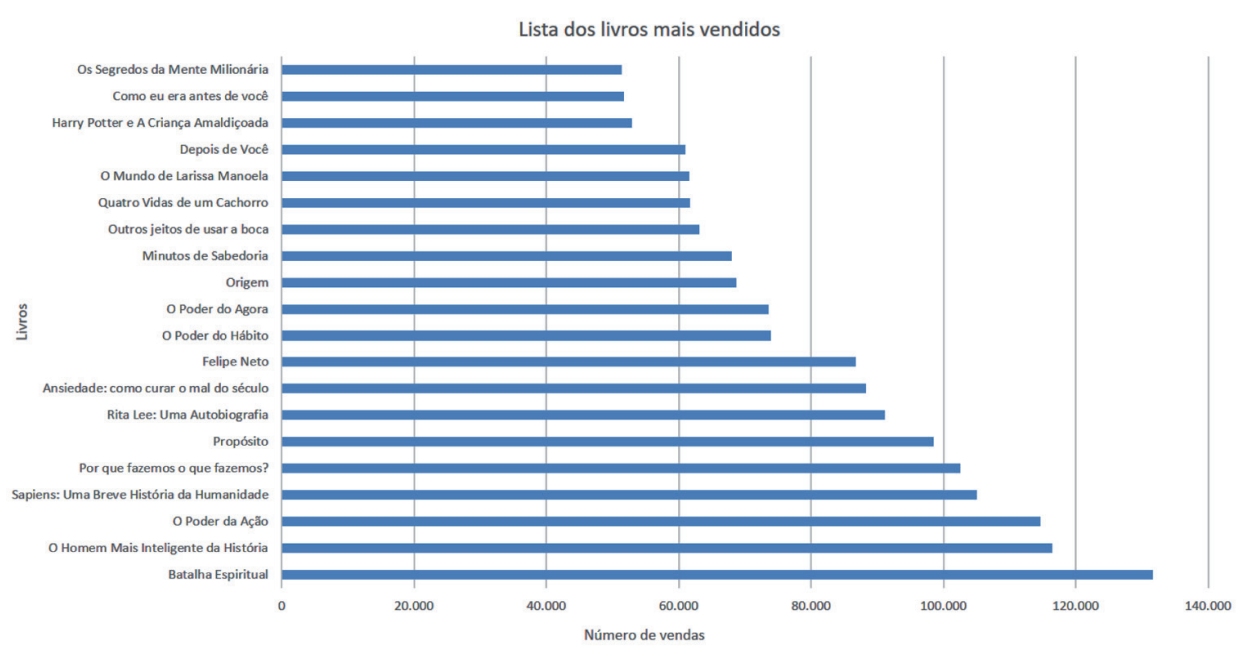

(Fonte: Publish News, 2017)

Relacionados com o meio artístico e personalidades da internet constam os títulos Felipe Neto (jornalista que ficou conhecido na internet após seu canal no youtube), O mundo de Larissa Manoela (atriz teen) e Rita Lee: Uma autobiografia. 
Quanto à literatura contemporânea, registamos Origem, Quatro vidas de um cachorro, Como eu era antes de você, Depois de você e Harry Potter e a Criança Amaldiçoada. Os três primeiros ganharam adaptações cinematográficas que alavancaram sua aparição nas mídias em geral, enquanto Harry Potter e a Criança Amaldiçoada, já conhecido devido à franquia de livros e filmes, também ganhou sua adaptação aos teatros britânicos e na Broadway, em Nova York. Ainda no contexto de literatura contemporânea, Outros jeitos de usar a boca aparece como o único livro de poesia. É importante sublinhar que este volume de Rupi Kaur, embora pelo tipo de repertórios utilizados (poesia) possa parecer procedente do campo da produção restrita ou erudita, é um sucesso comercial que passa longe das recomendações da academia, já que tem a sua origem nos círculos de leitoras feministas, como os "Leia mulheres" (https://leiamulheres.com.br/) estabelecidos em diversos estados brasileiros, e na promoção feita por influenciadoras feministas nas redes sociais. ${ }^{7}$

Por outro lado, por mais que apareça em escala de menor consumo dentro de um panorama comercial, a incidência de autores canonizados aparece atrelada especificamente à imagem acadêmica, conforme os dados de Eble (2014), numa pesquisa que procura identificar o cânone da literatura Brasileira na academia recorrendo ao estudo dos instrumentos próprios da instituição.

As tabelas abaixo representam a presença de autores brasileiros de acordo com: (1) número de citações em trabalhos, (2) seleção para leituras obrigatórias de vestibulares e (3) número de citações em livros didáticos, por serem estes fatores que parecem chave para um possível alargamento do leque de produtos e repertórios legitimados.

Tabela 1 - Citações em trabalhos acadêmicos

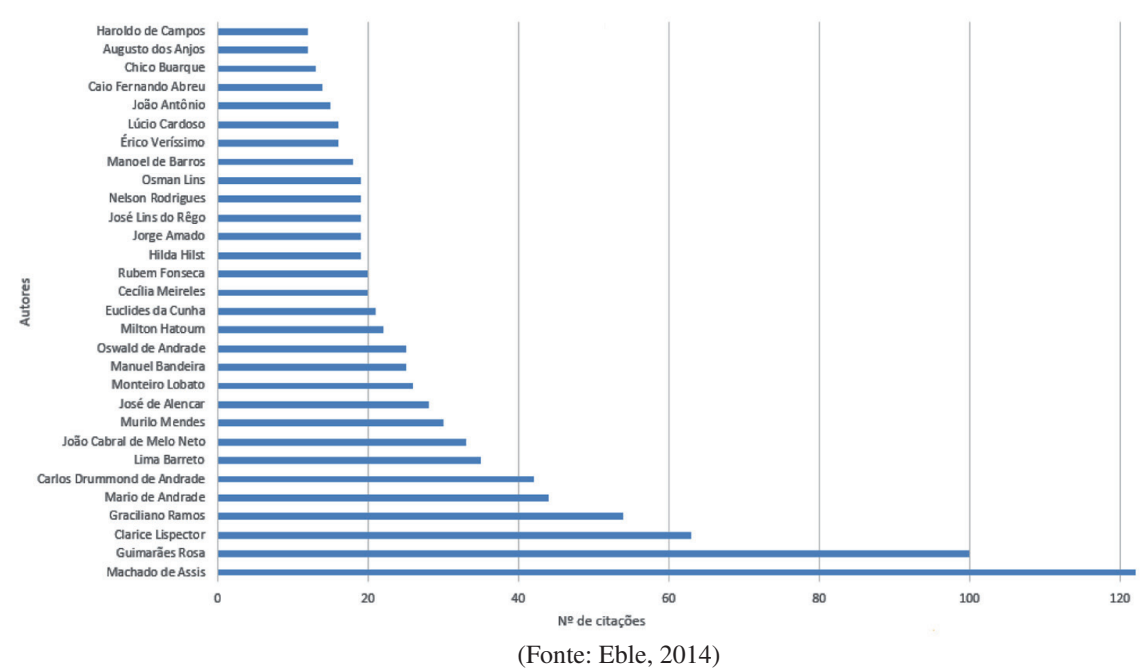

7 Kaur é presença habitual nas listas de livros mais vendidos no Brasil, mas a reação crítica pode ser sintetizada na opinião de Giovanna Dealtry, professora de Literatura Brasileira na Universidade Estadual do Rio de Janeiro (UERJ): 
A autora identifica os/as 30 produtores/as mais estudados/as: com mais de 100 citações estão Machado de Assis (122 citações) e Guimarães Rosa (100 citações). Em seguida, com um número de citações que varia entre 60 e 40 aparecem Clarice Lispector (63), Graciliano Ramos (54), Mario de Andrade (44) e Carlos Drummond de Andrade (42); entre 35 e 21 citações estão Lima Barreto (35), João Cabral de Melo Neto (33), Murilo Mendes (30), José de Alencar (28), Monteiro Lobato (26), Manuel Bandeira e Oswald de Andrade (25), Milton Hatoum (22), Euclides da Cunha (21). Por último, com até 19 citações, estão Cecília Meireles e Rubem Fonseca (20), Hilda Hilst, Jorge Amado, José Lins do Rêgo, Nelson Rodrigues e Osman Lins (19), Manoel de Barros (18), Érico Veríssimo e Lúcio Cardoso (16), João Antônio (15), Caio Fernando de Abreu (14), Chico Buarque (13), Augusto dos Anjos e Haroldo de Campos (12).

Tabela 2 - Leituras obrigatórias

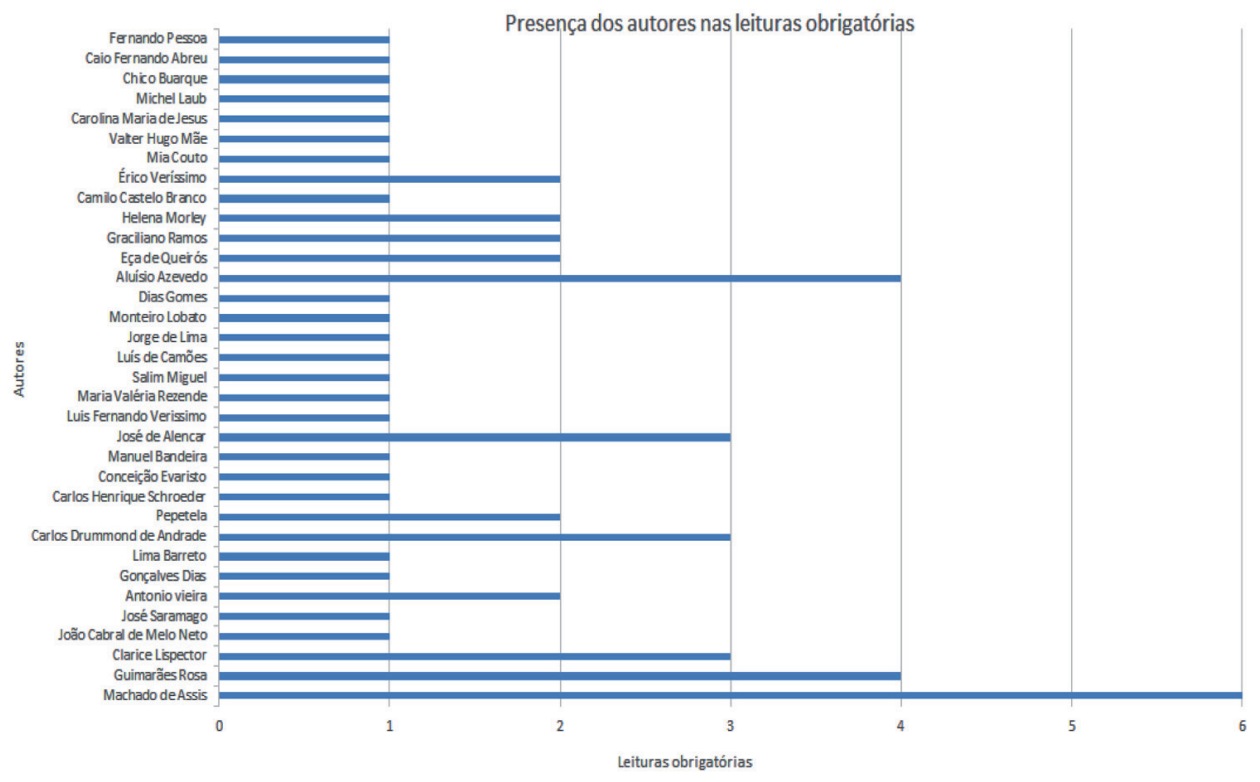

(Fonte: Super Vestibular, 2017)

"Kaur tem 2,5 milhões de seguidores no Instagram, e é possível entender como alguém que escreva sobre amor, perdas, medo de maneira acessível encontre uma legião de fãs. O problema desse novo perfil de escritor é que o sucesso em forma de likes impede tanto o amadurecimento da escrita como a intervenção de um editor" https://www1.folha.uol.com.br/ilustrada/2018/04/poemas-instantaneos-derupi-kaur-prendem-leitor-em-cliches.shtml

Nem na plataforma Scielo nem no banco de teses e dissertações da CAPES foi possível achar nenhum trabalhos de pesquisa sobre a poeta indiano-canadense. 
O impacto de grande parte destes autores também pode ser visto nas leituras obrigatórias dos principais vestibulares brasileiros no período de 2013 a 2017, compreendendo um número de 15 exames das universidades da PUCRS, UFRGS e UNICAMP, onde muitos dos nomes supracitados se repetem, como Machado de Assis, Guimarães Rosa, Clarice Lispector, João Cabral de Melo Neto, Lima Barreto, Carlos Drummond de Andrade, Manuel Bandeira, José de Alencar, Monteiro Lobato, Érico Veríssimo, Chico Buarque e Caio Fernando Abreu.

Como foi indicado acima, pode ser notada nas listas de leituras obrigatórias a presença de nomes não brasileiros tem a ver com a conformação do currículo escolar brasileiro, que inclui nomes da literatura portuguesa (sobretudo pré-independência) e, contemporaneamente, nomes oriundos das literaturas africanas de língua portuguesa.

Neste sentido, é possível dizer que um dos principais indicadores de consagração de produtores está em sua presença dentro dos vestibulares, pois trata-se de um contato inicial no meio acadêmico, mais especificamente através do vestibulando que o procurará como leitura obrigatória.

Ao lado dos nomes mais tradicionais como Machado de Assis, Guimarães Rosa, Clarice Lispector, Drummond de Andrade ou José de Alencar, podem ser vistas incorporações, em forma de resgate histórico e/ou valorização de textos ou produtores que não faziam parte do cânone ou que ocupavam posições marginais. Caio Fernando Abreu e Carolina Maria de Jesus, que foram introduzidos em leituras obrigatórias de vestibulares nos últimos anos, impulsionados provavelmente por movimentos sociais que reclamam visibilidade e representatividade no meio acadêmico. Mais recentemente (em 2018), podem citar-se os casos do romance abolicionista Úrsula de Maria Firmina dos Reis, escritora negra considerada a primeira romancista brasileira, que passou a integrar o vestibular da UFRGS, e o álbum Sobrevivendo no inferno de Racionais Mc que integra a lista do vestibular da UNICAMP, na seção de poesia, segundo anunciado pela instituição no dia 24 de maio de 2018.

Outro indicador da entrada do escritor no cânone está em sua capacidade posicionar-se ou ser posicionado em livros didáticos, sendo os seus utilizados como exemplos e referências literárias. A tabela abaixo evidencia os autores com maior número de menções, muitos deles encontrados tanto entre os citados em trabalhos acadêmicos quanto nas leituras obrigatórias de vestibulares. Nesta lista estão Carlos Drummond de Andrade (147), Fernando Pessoa (116), Manuel Bandeira (96), Luís de Camões (83), Oswald de Andrade (78), Laerte (62), Gregório de Matos e João Cabral de Melo Neto (59). 
Tabela 3 - Presença em livros didáticos

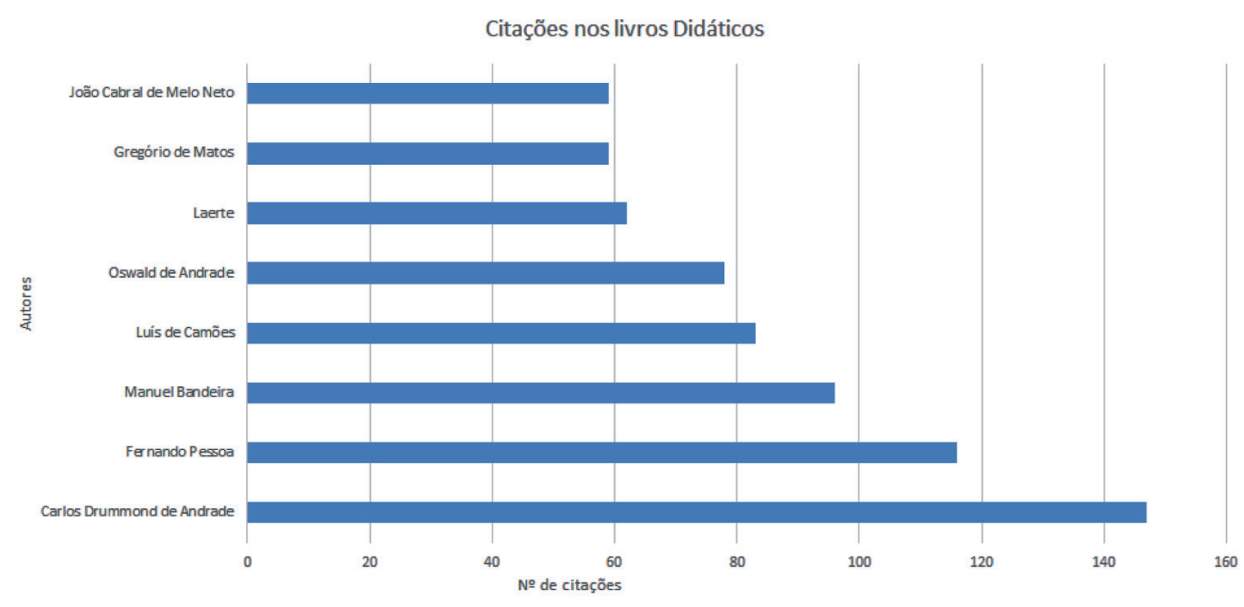

(Fonte: Eble, 2014)

Assim, como anteriormente, a incorporação de Laerte, cartunista e chargista transexual de grande popularidade, no meio de nomes historicamente consagrados pelos processos de canonização literária, parece mostrar uma tímida abertura para quem está às bordas do cânone, quer seja por pertencer a grupos socialmente minorizados (pessoas negras como Carolina de Jesus, Maria Firmina dos Reis e Racionais MC ou pertencentes à comunidade LGBT como Caio Fernando de Abreu e Laerte ) quer seja por produzirem textos inicialmente não considerados literários (Laerte e Racionais MC).

Contrastando o tipo de referência literária fornecida pela academia com as leituras declaradas na pesquisa Retratos da leitura (Failla, 2016), observa-se um predomínio de livros de cunho religioso, ficcional e de autoajuda, tanto quando as pessoas são questionados sobre as leituras que mais as marcaram quanto a respeito dos últimos lidos.

Considerando que esta pesquisa foi realizada entre novembro e dezembro de 2015, é importante elucidar alguns dos títulos presentes: Diário de um Banana, Turma da Mônica e $O$ Sítio do Pica-pau Amarelo são identificados como leituras infanto-juvenis; $A$ Culpa é das Estrelas, Cinquenta Tons de Cinza, Esperança, Cidades de Papel, A Maldição do Titã, A menina que roubava livros, A Cabana, Crepúsculo e Harry Potter ${ }^{8}$ são textos ficcionais caracterizados pela sequencialidade da narrativa em várias partes e/ou pela adaptação para o meio audiovisual; a Bíblia, Ágape, Livro dos Espíritos, Violetas na Janela, Philia e A Única Esperança são textos de cunho religioso cristão; Casamento Blindado, O Monge e o Executivo, Ninguém é de ninguém e $O$ Código da Inteligência são livros de autoajuda escritos por figuras relativamente populares no país, assim como Muito mais que cinco minutos, livro de uma youtuber brasileira.

8 Além de ser um best-seller mundialmente famoso, sua aparição na lista pode ter relação com a notícia da produção de um spin off da saga: Animais Fantásticos e Onde Habitam. 


\section{Último livro lido ou que está lendo}

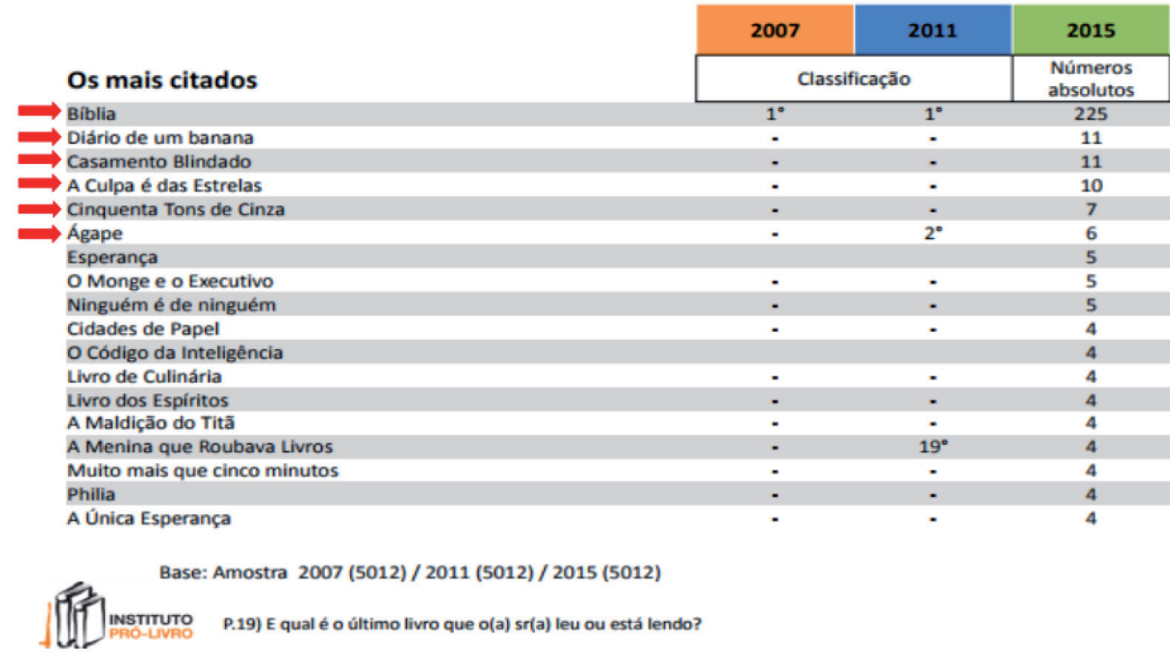

\section{Livro mais marcante: os mais citados}

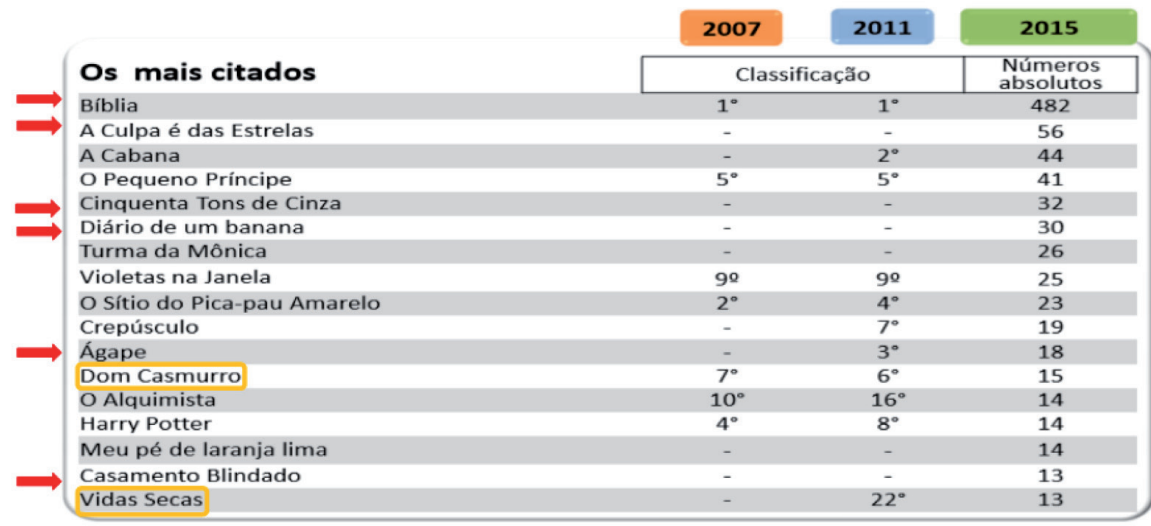

$\sqrt{\text { Instiruto }}$

Base: Quem estudou/ sabe ler / escrever 2007 (4210) / 2011 (4560) / 2015 (4579)

P.42) Qual é o livro que mais marcou o(a) $\operatorname{sr}(a)$ ou que o(a) $\operatorname{sr}(a)$ mais gostou de ler?

As obras sinalizadas em vermelho nas tabelas são aquelas que surgem nas respostas fornecidas pelas pessoas entrevistadas. Observe-se que colocamos em diálogo duas gráficas que se correspondem com respostas localizadas em lugares distantes do relatório, o que pode fazer pensar que as perguntas foram formuladas com alguma separação temporal. 
As referências canonizadas (marcadas em amarelo) a Machado de Assis e Jorge Amado aparecem apenas na categoria "mais marcantes" parecendo remeter a uma leitura do passado escolar evocado. Ao lado da figura central do cânone (Machado) e de uma figura ambígua quanto à sua legitimação (Amado) aparece um autor que ficou ligado apenas ao universo infantil, e com uma posição cada vez mais enfraquecida, como é Monteiro Lobato. Quando a pergunta é referida à prática leitora presente, apenas aparecem best-sellers e outros tipos de produção não legitimada pela academia, verificando-se a função atribuída por Bourdieu (2005: 123) ao sistema escolar:

Não seria possível compreender inteiramente as caraterísticas próprias da cultura erudita sem levar em conta os diferentes tratamentos a ela impostos pelo sistema de ensino, instrumento indispensável de sua reprodução e, ao menos de modo indireto, ou seja, por intermédio da contribuição que traz à reprodução dos produtores e à sua ampliação.

\section{Escritores que mais gostam - Pergunta nova em 2015}

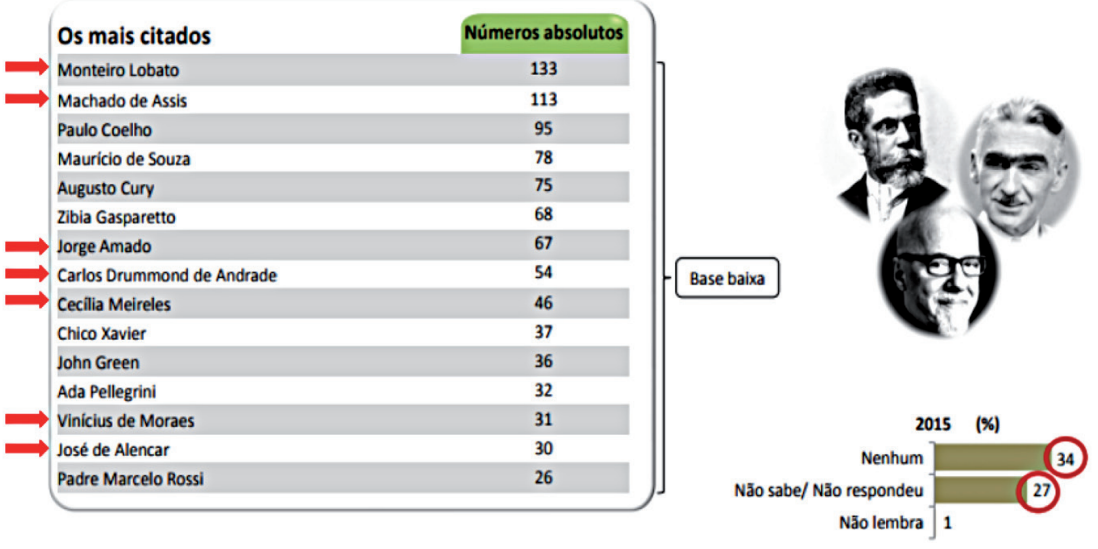

Base: Amostra (5012)

P.41) Quais são os escritores que $0($ a) sr(a) mais gosta ou gostou de ler?

Ao verificar os escritores declarados como preferidos dos entrevistados, o cânone escolar reaparece com força, pois os autores destacados são aqueles que fazem parte das leituras escolares brasileiras como representantes do cânone literário nacional como Machado de Assis, Jorge Amado, Carlos Drummond de Andrade, Cecília Meireles, Vinícius de Moraes e José de Alencar; ou por serem caracterizados como produtores do universo infanto-juvenil como Monteiro Lobato, que tem um papel de destaque por sua série infantil O Sítio do Pica-pau Amarelo, e o cartunista Maurício de Souza, responsável pela série A turma da Mônica. 
Os outros produtores seguem as linhas já previstas de best-seller, autoajuda e espiritualidade: Paulo Coelho e John Green são escritores conhecidos por suas obras ficcionais; Augusto Cury e Zíbia Gasparetto por seus livros de autoajuda; Chico Xavier e Padre Marcelo Rossi por livros religiosos e Ada Pellegrini por sua obra como jurista.

Percebe-se que, quando os entrevistados são questionados sobre quais livros foram mais marcantes ou sobre aqueles que mais gostam, há a presença, mesmo que minoritária, de livros nacionais canonizados, e logo em seguida, na pergunta sobre quais escritores de que mais gostam, os autores destes livros aparecem no topo. Esta correlação mostra uma característica recorrente: a lista de escritores está mais recheada de produtores legitimados do que a de livros. Talvez a facilidade de lembrar nomes aprendidos na escola tenha relevância para explicar este deslocamento, mas acreditamos que também seja relevante o que Bourdieu (2011: 236) denominou o "efeito da legitimidade", pois estes autores ocupam um lugar de prestígio muito maior que John Green, por exemplo, que é o autor do best-seller que se encontra no top 5 de livros mais marcantes/último lido. $\mathrm{Na}$ nossa análise, seria compreensível a pessoa, sentindo-se inquirida (e, talvez, avaliada), tentar oferecer o que acredita ser a sua melhor resposta invocando nomes procedentes do conhecimento consagrado pela escola. Considera-se também a presença das leituras obrigatórias dos vestibulares nestas listas, visto que nomes como Machado de Assis e Jorge Amado são constantes tanto nas obrigatórias quanto nas leituras (ditas) feitas no lazer.

Para avançar na análise comparativa entre os produtos literários legitimados e as práticas leitoras declaradas, a seguinte gráfica elucida quantitativamente em azul o número de autores presentes nas leituras indicadas, no relativo ao ano 2015 pelas universidades que alcançaram nota máxima (7) da CAPES para os seus programas de Pós-Graduação em Letras. Em salmão mostra-se o volume de produtores que aparecem em comum entre as universidades e, em verde, salienta-se os que também foram citados na pesquisa Retratos da Leitura (Failla, 2016).

\section{Vestibulares 2015 nota 7/CAPES}

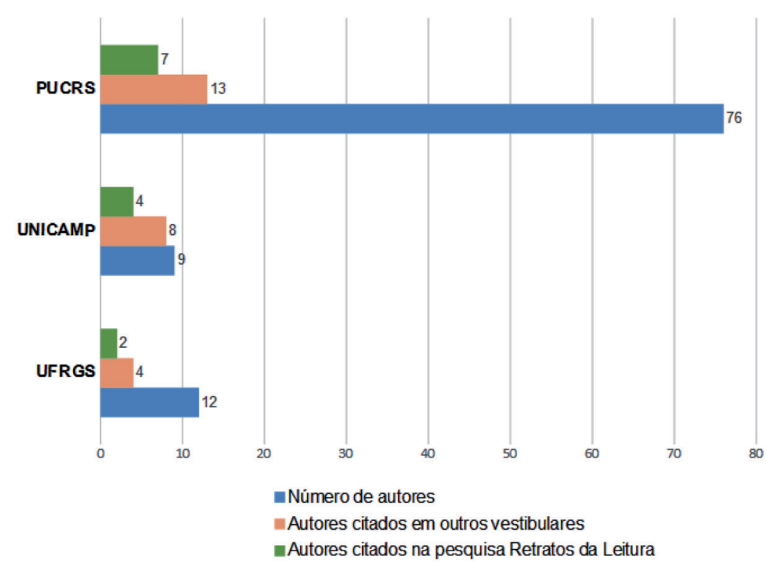


Os dados apresentados até aqui levantam um questionamento: a leitura das produções que integram o cânone, por mais relevante que seja dentro da academia, limita-se ao desenvolvimento acadêmico ou pode ser considerada como uma prática de leitura espontânea das pessoas leitoras? A tentativa de responder esta pergunta resultou no surgimento de questionamentos éticos sobre o investimento público dedicado à promoção da leitura, sobre os baixos níveis de letramento e, finalmente, sobre os possíveis impactos na autoestima de leitores e leitoras quando as suas escolhas são sistematicamente desconsideradas e até coagidas pelas políticas públicas e a escola. Em última instância, estes questionamentos levam a um maior: qual é a comunidade potencialmente afetada ou interessada nos resultados da pesquisa dos Estudos Literários?

Tradicionalmente, esta tem sido constituída pelo conjunto de acadêmicos e acadêmicas dedicados aos próprios Estudos Literários, mas se entendermos a Literatura na sua dimensão de prática social, com valores e significados sociais incorporados, então a comunidade de referência deveria ser entendida como aquela composta pelas leitoras e os leitores, junto com agentes sociais no âmbito da educação e do letramento.

Os efeitos destas perspectivas em conflito são duplos. Em primeiro lugar, mostram o vínculo fraco que existiria entre o que os Estudos Literários pesquisam e o estado real do sistema literário (seguindo a definição de Even-Zohar), e por isso parece um questionamento legítimo perguntar-se se aqueles estão cumprindo, de fato, o seu objetivo científico quando ignoram as forças e dinâmicas do sistema. Em segundo lugar, com base na perspectiva sociológica de Bourdieu relativa à educação como reprodutora do habitus e da classe social, é também necessário questionar até que ponto políticas públicas e educativas dirigidas a populações vulneráveis, como a infância, podem ser mais prejudiciais do que benéficas se se estruturam na oposição de duas concepções culturais de literatura como prática social, uma delas coagindo a outra, sendo que a que é apresentada como o caminho para o sucesso social e acadêmico exclui os repertórios e materiais mais procurados pelo público leitor.

\section{CONCLUSÕES}

Com base nos dados apresentados, pode-se afirmar que no Brasil a capacidade prescritora da academia sobre o mercado editorial é fraca, uma vez que a presença do cânone dentro do comércio literário é reduzida e vinculada às indicações escolares de leituras obrigatórias, com especial relevância para os vestibulares das principais universidades federais.

Quando não direcionada pela dinâmica de acesso ao ensino superior, detectamos a forte convergência da leitura de ficção com outras mídias como o cinema, TV e Internet, por meio de produtos que funcionam em diversos campos culturais simultaneamente, transformando-as em blockbusters em vários deles.

Constatou-se que as leituras obrigatórias dos vestibulares não se encontram de acordo com os gostos manifestados por pessoas leitoras nas pesquisas consultadas: os 
indicativos mostram que há uma procura por livros, mas não aqueles estabelecidos como canônicos e legitimados pela escola e a academia. Em consequência, qualquer política que procure o letramento por meio da leitura deve tomar como base os interesses da comunidade leitora. Repare-se em que, como visto na discussão dos dados, estes interesses não são exclusivamente ficcionais (com grande peso da chamada leitura de autoajuda), e não é a nossa proposta redirecionar o gosto para uma leitura exclusivamente de ficção.

Focar os Estudos Literários num conjunto (de)limitado de textos e autores pode ser compreensível numa perspectiva patrimonial ou histórica, como indicador para a reconstrução histórica da literatura como disciplina e objeto de estudo. No entanto, limitar o fenômeno contemporâneo da literatura ao estudo de um conjunto de textos consagrados e a uns repertórios em exclusivo é a negação das responsabilidades éticas da pesquisa.

Em sociedades altamente mediadas pelo letramento, é vital que as pessoas consigam desenvolver as habilidades de ler e escrever com eficácia alta, pois disso depende o exercício dos seus direitos de cidadania. Ao mesmo tempo, pesquisa na área dos estudos cognitivos (Jaén e Simon, 2013) mostra que a leitura de ficção pode contribuir no desenvolvimento humano. Portanto, novos caminhos devem ser explorados para a promoção da leitura (literária ou não), particularmente em contextos de baixo nível de letramento, a fim de ir além da propagação de um cânone literário nacional, e essas novas estratégias devem proceder do conhecimento das comunidades de leitoras e leitores reais ou possíveis.

Em qualquer caso, a proposta não pretende uma tradução escolar em forma de cadeira ou de novo conteúdo programático, nem parte de uma superioridade ética do sujeito leitor, como foi indicado no início do texto, mas da procura de estratégias que deem resposta ao desiderato expresso no enunciado "ler ajuda a vencer na vida", que mostra uma percepção de desvantagem social e cidadã em pessoas com pouco ou nulo acesso à leitura. 


\section{REFERÊNCIAS BIBLIOGRÁFICAS}

ABREU, Márcia (2001) Diferença e desigualdade: preconceitos em leitura. MARINHO, Marildes (Org.) Ler e navegar: espaços e percursos da leitura. Campinas-SP: Mercado de Letras; Belo Horizonte, MG: Ceale, pp. 139-157.

ARENA, Luís Paulo (2018) Bibliotecas comunitárias: um estudo de inspiração etnográfica sobre as práticas de leitura, seus significados e efeitos nas interações culturais de jovens em uma comunidade urbana periférica de Porto Alegre/RS. Tese de Doutorado em Letras, a ser defendida. Porto Alegre: Centro Universitário Ritter dos Reis.

BRASIL. LEI N ${ }^{\circ}$ 5.540, DE 28 DE NOVEMBRO DE 1968. Fixa normas de organização e funcionamento do ensino superior e sua articulação com a escola média, e dá outras providências. Brasília, DF, nov 1968. Disponível em <http://www2. camara.leg.br/legin/fed/lei/1960-1969/lei-5540-28-novembro-1968-359201-publicacaooriginal-1-pl.html>. Acesso em 28 de junho de 2018.

BRASIL. LEI N 12.711, DE 29 DE AGOSTO DE 2012. Dispõe sobre o ingresso nas universidades federais e nas instituições federais de ensino técnico de nível médio e dá outras providências. Brasília, DF, ago 2012. Disponível em <http://www. planalto.gov.br/ccivil_03/_ato2011-2014/2012/lei/112711.htm>. Acesso em 28 de junho de 2018.

BOURDIEU, Pierre (2011) “A leitura: uma prática cultural. Debate entre Pierre Bourdieu e Roger Chartier”. CHARTIER, Roger (Org.). Práticas da leitura. 5. ed. São Paulo: Estação Liberdade, pp. 231-253.

BOURDIEU, Pierre (2015) "O mercado dos bens simbólicos". Em A economia das trocas simbólicas. $6^{\mathrm{a}}$ ed. São Paulo: Editora Perspectiva.

CANDIDO, Antonio (2004) "O direito à literatura”. Vários escritos. São Paulo/Rio de Janeiro: Duas Cidades/Ouro sobre Azul, pp. 169-191.

CASTRILlÓN, Silvia (2011) O direito de ler e de escrever. São Paulo: Pulo do Gato.

DEALTRY, Giovanna (2018) "Poemas instantâneos de Rupi Kaur prendem leitor em clichês”. Folha de São Paulo, 21/04/2018. Disponível em https://www1.folha.uol. com.br/ilustrada/2018/04/poemas-instantaneos-de-rupi-kaur-prendem-leitor-em-cliches.shtml. Acesso 16 de junho de 2018.

EBLE, Laeticia (2014) A literatura brasileira e a permanência do cânone na academia. Revista Observatório Itaú Cultural. São Paulo. n.12, p.142-153.

EVEN-ZOHAR, Itamar (2005) Papers in Culture Research. Tel Aviv: Unit of Culture Research, Tel Aviv University.

FAILLA, Zoara (2016). Retratos da leitura no Brasil 4. São Paulo: Imprensa Oficial do Estado de São Paulo, Instituto Pró-Livro.

HORELlOU-LAFARGE, Chantal; SEGRÉ, Monique (2010) Sociologia da Leitura. Cotia-SP: Ateliê Editorial. 
IBGE, Diretoria de Pesquisas, Coordenação de Trabalho e Rendimento. Pesquisa Nacional por Amostra de Domicílios 2007/2015. Disponível em https://brasilemsintese.ibge.gov.br/educacao/taxa-de-analfabetismo-das-pessoas-de-15-anos-ou-mais. html. Acesso 26 de junho de 2018.

INEP. Sistema de avaliação da Educação Básica. Avaliação nacional da alfabetização. Edição 2016. Brasília: MEC, 2017. Disponível em http://portal.mec.gov. br/index.php?option=com_docman $\&$ view $=$ download \&alias $=75181$-resultados -ana-2016-pdf\&category_slug=outubro-2017-pdf\&Itemid=30192. Acesso 24 de junho de 2018.

JAÉN, I; SIMON, J. J. (2013, ed.) Cognitive Literary Studies: Current Themes and New Directions. Austin: the University of Texas Press.

LAJOlO, Marisa; ZILBERMAN, Regina (2003) A formação da leitura no Brasil. 3. ed. São Paulo: Ática.

LIMA, Ana; RIBEIRO, Vera Masagão; CATELLI Jr, Roberto. Indicador de analfabetismo funcional INAF. Estudo especial sobre alfabetismo e mundo do trabalho. São Paulo: Instituto Paulo Montenegro, 2016. Disponível em http://acaoeducativa. org.br/wp-content/uploads/2016/09/INAFEstudosEspeciais_2016_Letramento_e_ Mundo_do_Trabalho.pdf. Acesso em 16 de outubro de 2017,

PETIT, Michèle (2008) Os jovens e a leitura: uma nova perspectiva. São Paulo: Editora 34 .

PETIT, Michèle (2012) A arte de ler ou como resistir a diversidade. São Paulo: Editora 34.

PETIT, Michèle (2013) Leituras: do espaço íntimo ao espaço público. São Paulo: Editora 34 .

PROLER. "Sobre o Proler". Disponível em http://proler.culturadigital.br/oproler/. Acesso em 29 de junho de 2018.

PUBLISH NEWS. Lista de Mais Vendidos Geral de 2017. Página Online. Disponível em: <http://www.publishnews.com.br/ranking/anual>. Acesso em 18 de outubro de 2017.

PUCRS. Conteúdo programático vestibular 2013/2017. Disponível em <http://vestibular.pucrs.br/wp-content/uploads/2017/04/manual-do-candidato.pdf>. Acesso em 13 de outubro de 2017.

SUPER VESTIBULAR. Obras literárias. Página Online. Disponível em: <http://vestibular.mundoeducacao.bol.uol.com.br/obras-literarias/>. Acesso em 18 outubro de 2017.

TORRES FEIJÓ, Elias J. (2015) “Tourism and local community: unperceived and imperceptible risks and socially responsible research (SRR). First stages to work SRR with traders". In 10th CTS Conference Proceedings. Disponível em https://www. researchgate.net/publication/284730807_Tourism_and_local_community_unperceived_and_imperceptible_risks_and_socially_responsible_research_SRR_First_ stages_to_work_SRR_with_traders . Acesso em 15 de outubro de 2017. 
TORRES FEIJÓ, Elias J. (2016) "Ler, sem ética nem moral. Contributos da psicologia cognitiva e ética na e da literatura'. Leitura, história e ensino. Organizado por Tania Rösing e Regina Zilberman. : Porto Alegre: Edelbra Editora Ltda, pp. 49-89.

UFRGS. Leituras obrigatórias 2015. Disponível em <http://www.ufrgs.br/coperse/concurso-vestibular/anteriores/2015/leituras-obrigatórias>. Acesso em 13 de outubro de 2017.

UNICAMP. Lista de livros 2013/2015. Disponível em <http://www.comvest.unicamp. br/vestibulares-anteriores/vestibular-2015/lista-de-livros-vestibular-2015/>. Acesso em 15 de outubro de 2017. 